\title{
DE REDES, JERARQUÍAS Y CONSPIRACIONES, O CÓMO SE FABRICA UN BESTSELLER HISTÓRICO NEOCONSERVADOR ${ }^{\alpha}$
}

\author{
Of networks, hierarchies and conspiracies, or how a historic \\ neoconservative bestseller is made
}

\author{
Antonio Viñao ${ }^{\beta}$ \\ Fecha de recepción: 05/10/2020 • Fecha de aceptación: 12/10/2020
}

Resumen. Este ensayo crítico constituye un extenso comentario-análisis de la obra del historiador Niall Ferguson titulada La plaza y la torre. El papel oculto de las redes en la historia: de los masones a Facebook, traducida y publicada en castellano en 2018. El libro se halla situado, según su autor, en una vía intermedia entre la historiografía dominante, que ha tendido a subestimar la importancia de las redes, y los teóricos de la conspiración, que por lo general la exageran. Su propósito central es el de destacar la relevancia que han tenido y tienen las redes sociales en los acontecimientos y procesos históricos. El análisis aquí efectuado pretende desentrañar cómo dicho obra constituye un buen ejemplo, desde el ámbito neoconservador estadounidense, de cómo fabricar un bestseller histórico al servicio de dicha ideología.

Palabras clave: redes sociales; teorías conspirativas; jerarquías; historiografía neoconservadora.

Abstract. This critical essay is an extensive commentary-analysis of the work of historian Niall Ferguson entitled The Square and the Tower. Networks and Power from the Freemasons to Facebook translated and published in Spanish in 2018. The book is located, according to its author, on an intermediate

\footnotetext{
a Agradezco a Jack Owens, Profesor emérito de Historia e Investigador Distinguido de la Idaho State University y buen amigo, la lectura de este texto y las observaciones realizadas sobre el mismo. La responsabilidad, como es obvio, de lo que en él se dice, corresponde al autor.

${ }^{\text {B }}$ Facultad de Educación. Universidad de Murcia. Campus universitario de Espinardo. 30100 Murcia. España.avinao@um.es
} 
path between dominant historiography, which has tended to underestimate the importance of networks, and conspiracy theorists, who usually exaggerate it. Its central purpose is to highlight the relevance that social networks have had and have in historical events and processes. The analysis carried out here is intended to unravel how this work is a good example, from the United States neoconservative field, of making a historic bestseller at the service of that ideology.

Keywords: social networks; conspiratorial theories; hierarchies; neoconservative historiography.

La publicación en 2018 de la edición en castellano de la obra de Niall Ferguson La plaza y la torre. El papel oculto de las redes en la historia: de los masones a Facebook (Barcelona: Random House) ha ido acompañada, en el último año, de algunas recomendaciones y referencias positivas de diversos ensayistas y escritores en Babelia, el suplemento literario de EL País. Esta es la razón que me indujo, junto con el título (justo es decirlo), a su lectura. ${ }^{1}$ También el hecho de que en los últimos años hayan proliferado en la historiografía educativa los trabajos y monográficos de revistas prestigiosas sobre el relevante papel de las redes institucionales, personales, nacionales y sobre todo transnacionales en las transferencia y difusión de ideas, métodos, sistemas y modelos educativos, así como sobre las influencias, viajes, traducciones, conexiones, formación de sociedades, grupos informales, etc., que están detrás de dichas transferencia y difusión. ${ }^{2}$ Influyó también en la decisión la notoriedad del autor, con abundante obra anterior traducida al castellano, ${ }^{3}$ al que en la portadilla interior se le califica como «el historiador británico más brillante de la actualidad», profesor e investigador en las más reputadas universidades inglesas y estadounidenses que, en las primeras páginas, se autodefine como «historiador interconectado», integrado en «redes económicas y políticas» como el Foro Económico

\footnotetext{
1 Es evidente que traducir, en el título, Networks and Power por El papel oculto de las redes en la historia solo se explica por razones comerciales.

2 Por ejemplo, los monográficos de Paedagogica Histórica sobre «Networks and the History of Education» (XLIII, n. ${ }^{\circ}$ I, 2007) e "Internationalisation in Education: Issues, Challenges, Outcomes» (L, n. ${ }^{\circ}$ I-II, 2014)

3 Estos son los títulos y años de las obras traducidas y publicadas, todas ellas, por la editorial Debate: Coloso (2005), El Imperio británico (2005), La guerra del mundo (2007), El triunfo del dinero (2010) y Civilización (2012). Una pequeña parte de la obra de un historiador prolífico que supera ya los catorce títulos.
} 
Mundial y el más que selecto grupo Bilderberg, ${ }^{4} \mathrm{y}$ miembro de tres clubs londinenses y uno neoyorkino, así como de los consejos de administración de «tres entidades corporativas: un gestor de activos globales, ${ }^{5}$ un grupo de expertos británicos y un museo de Nueva York» (p. 15). Por fin, me dije, he aquí alguien que no solo cree saber, sino que debe saber por dónde va el mundo e influye en quienes determinan por dónde va a ir. Como él mismo reconoce, «no soy una persona muy jerárquica: por elección soy un tío de redes» por lo que, "pese a estar relativamente bien interconectado»-o sea, bien informado acerca de por dónde van las cosas- «casi no tengo poder».

No estamos, pues, ante una persona poderosa económica o políticamente, sino ante un intelectual influyente que se codea y mueve en los entresijos del poder económico y político -no así, según parece, del religioso, un tema prácticamente ignorado en el libro- desde una posición ideológica afín al Partido Republicano estadounidense. De ahí que Ferguson diga, con agradecimiento, que el libro «es en sí mismo producto de una red» al haber sido escrito en y con el apoyo de la Institución Hoover, un think tank de dicho partido que constituye, a diferencia del mundo universitario - donde, según afirma, no se valora la «diversidad

\footnotetext{
4 «El club, conferencia, grupo o foro Bilderberg es una reunión anual a la que asisten aproximadamente las 130 personas más influyentes del mundo, mediante invitación. Los miembros de este grupo se reúnen en complejos de lujo ubicados en Europa, Norteamérica y Asia occidental, donde la prensa no tiene ningún tipo de acceso, y sus oficinas están en Leiden (Países Bajos). El nombre de este club procede del hotel en el que tuvo lugar la primera reunión, en los Países Bajos». Se constituyó en 1954 con el propósito «hacer un nudo alrededor de una línea política común entre Estados Unidos y Europa en oposición a Rusia y al comunismo». En: https://es.wikipedia.org/wiki/Grupo_Bilderberg (consulta efectuada el 5 de septiembre de 2020).
}

5 Fondo o activo global: «este tipo de fondos pueden invertir en cualquier tipo de activo (obligaciones, bonos, acciones, activos del mercado monetario, activos inmobiliarios, derivados, materias primas...), en cualquier tipo de divisa (nacional e internacional) o cualquier mercado (nacional o internacional, renta fija, renta variable, mercado monetario, mercado de divisas, mercado inmobiliario...). En estos fondos no es necesario fijar los porcentajes de inversión destinados a cada activo.

En Estados Unidos, se considera fondo global aquel fondo que incluye en su cartera de inversión, al menos un $25 \%$ de acciones de mercados internacionales. El valor de estos fondos está en función de las fluctuaciones en los tipos de cambio y en la riqueza de las economías internacionales en las cuales se invierte. También se le denomina fondo mundial (World Fund).

Otra acepción de fondo global [...] se corresponde con aquel fondo que invierte en cualquier lugar del mundo». En: https://guiasjuridicas.wolterskluwer.es/Content/Documento.aspx?params=H4sIAAAAAAAEAMtMSbF1jTAAASNjS0NDtbLUouLM_DxbIwMDINfAFCSQmVbpkp8cUlmQapuWmFOcCgBoYF-sNQAAAA==WKE (consulta efectuada el 7 de septiembre de 2021). 
intelectual»-, «un raro -si no único- bastión de la libre investigación y del pensamiento independiente» (p. 21). ${ }^{6}$

\section{UNA VÍA INTERMEDIA ENTRE LAS REDES Y LAS TEORÍAS CONSPIRATORIAS}

Ya en la primera página Ferguson rechaza el extendido uso de la palabra red para apoyar a los «teóricos de la conspiración» que albergan «la creciente sospecha de que el mundo está controlado por redes poderosas y exclusivas: los banqueros, el establishement, el sistema, los judíos, los masones, los Illuminati... Casi todo lo que se ha escrito sobre este tema es un puro disparate», nos dice. Para demostrarlo dedicará después algunos capítulos a los Illuminati, los Rothschild o a la red financiera de Soros y la quiebra del Banco de Inglaterra como ejemplos de atribuciones erróneas de conspiraciones causantes de cambios y convulsiones económicas o sociales. El problema reside en que el análisis que efectúa de otras redes cubre, nada más y nada menos, que desde la de la red de los Médici en la Florencia del siglo XIV a las FANG -«colmillo»-(Facebook, Amazon, Netflix, Google) y las BAT -«murciélago»-chinas (Baidu, Alibaba y Tencent) pasando por la red comercial portuguesa establecida en el siglo XVI, la de los mestizajes o de índole «familiar multicultural» en la que se asentó la conquista española de América, las redes surgidas gracias a la conjunción de la imprenta con la Reforma,

\footnotetext{
6 «The Hoover Institution on War, Revolution, and Peace is an American public policy think tank and research institution located at Stanford University in California. Its mission statement outlines its basic tenets: representative government, private enterprise, peace, personal freedom, and the safeguards of the American system. The institution is generally described as conservative». En: https://en.wikipedia.org/wiki/Hoover_Institution (consulta efectuada el 5 de septiembre de 2020). Otra versión es la proporcionada por la red Voltaire: «Fundada en la universidad de Stanford por el ex presidente Herbert Hoover, la institución que lleva su nombre creó una gigantesca biblioteca sobre las guerras del siglo XX y los regímenes comunistas. Esta institución universitaria, financiada por grandes empresas y en la que se encuentran empleados algunos de los que apuestan por el Partido Republicano, ambiciona poner la investigación científica al servicio de la defensa del "sistema norteamericano"». En: https://www.voltairenet.org/article123679.html (consulta efectuada el 5 de septiembre de 2020).
}

Dos observaciones colaterales. La primera es que Estados Unidos es un país ubicado en América y, más en concreto, en Norteamérica. O sea, no es América ni siquiera Norteamérica. El uso de los términos América o Norteamérica para referirse a Estados Unidos es una falaz sinécdoque destinada a encubrir el dominio de este país sobre el continente americano. La segunda se refiere a la consideración de la Institución Hoover como «un raro -si no único- bastión de la libre investigación y el pensamiento independiente»: la frase resulta ofensiva para cualquier lector de mediana inteligencia salvo que se trate de una broma. Grave cosa es confundir la libertad y el grado de independencia de una institución o red con el hecho de que uno se halle o no cómodo, como pez en el agua, en ella. 
las redes científicas y comerciales europeas del siglo XVII, las intelectuales e ideológico-políticas que originaron las revoluciones francesa y estadounidense, la red de la Casa de Sajonia-Coburgo-Gotha, la «red del vapor» que hizo posible la revolución industrial, las redes locales y privadas que sostuvieron el Imperio británico, la red oxoniense de Milner que sentaría las bases del apartheid en Sudáfrica y «concebía un futuro viril, marcial, imperial y heterosexual» a diferencia de la red "amanerada, pacifista, liberal y homosexual» de «los Apóstoles» de Cambridge (el grupo de Bloomsbury con sus «complicaciones amorosas»y, por supuesto, Keynes a quien, según se apresura a contarnos, no le interesaban como estudiante las matemáticas sino «los hombres»), el papel destacado de los judíos en el mundo económico e intelectual alemán entre 1830 y 1930, la red de espías británicos (el «Círculo de los Cinco») al servicio de la KGB soviética, la mafia, la guerra de guerrillas del general Walker en el Sureste asiático (como ejemplo de red informal), las redes de poder de Kissinger y de Nixon-Ford, la génesis de Internet, el Foro Económico Mundial y Davos, las redes de la oposición polaca al régimen comunista, Al Qaeda y los atentados del 11-S, la quiebra de Leman Brothers en 2008 y sus consecuencias en la red financiera mundial, las redes salafista y yihadista de ISIS, la red de guerrillas creada por el gobierno estadounidense para combatir la yihad, la WEB 2.0, el papel de las redes en el Brexit y en la elección de Trump, la red del partido comunista chino y la ciberguerra en la red de redes.

Sin embargo, como sugiere el subtítulo del libro con sus referencias a lo «oculto» -término que no figura en el original inglés- y los «masones», en esta amplia diversidad más de uno de los casos analizados parece estar destinado a que se llegue a la conclusión opuesta a la pretendida por Ferguson: la de que hay algo de verdad en esa relación entre las redes y las explicaciones o teorías conspiratorias. ${ }^{7} \mathrm{O}$, en todo caso, a la idea de que este ha sido y es un mundo de redes en conflicto, sin relación o en colaboración, y que solo el conocimiento de su composición, estructura y funcionamiento puede ayudarnos a entender tanto el pasado como la realidad actual. Es lo que Ferguson denomina, al referirse al

\footnotetext{
7 No se aleja mucho de esta impresión la manifestada irónicamente por Andrew Anthony en su crítica del libro en The Guardian: «such is Ferguson's restless desire to uncover connectedness that he can sound like a conspiracy theorist». En https://www.theguardian.com/books/2017/sep/24/niall-ferguson-square-and-tower-networks-hierarchies-review (consulta efectuada el 20 de septiembre de 2020).
} 
propósito del libro, «una vía intermedia entre la historiografía dominante, que ha tendido a subestimar la importancia de las redes, y los teóricos de la conspiración, que por lo general la exageran» (p. 32).

\section{REDES Y JERARQUÍAS}

En efecto, esta es la tesis central del libro: «hasta hace muy poco [...] los historiadores profesionales tendían a pasar por alto el papel de las redes o, cuanto menos a minimizarlo. Aun hoy la mayoría de los historiadores académicos suelen centrarse en el tipo de instituciones que crean y conservan archivos», o sea, en aquellas instituciones «jerárquicas» que, por su carácter institucional, dejan huellas, rastros y testimonios documentales fácilmente accesibles. Sin embargo, añade, «mis investigaciones y mi experiencia me han enseñado a recelar de la tiranía de los archivos. A menudo los mayores cambios de la historia son logros de grupos de personas poco documentados y organizados de manera informal» (pp. 13-14). En definitiva, «las redes sociales siempre han sido mucho más importantes en la historia de lo que han reconocido la mayoría de los historiadores» (p. 20).

Este libro trata sobre el irregular flujo y reflujo de la historia. Distingue largas épocas en que las estructuras jerárquicas dominaron la vida humana de aquellos otros períodos -más raros, pero a la vez más dinámicos- en que las redes llevaron las de ganar, gracias en parte a diversos cambios producidos en la tecnología. Por decirlo de una manera sencilla, cuando la jerarquía está a la orden del día, el poder de cada uno depende del peldaño que ocupa en el escalafón ordenado de un Estado, empresa o institución similar verticalmente ordenada. En cambio, cuando las redes obtienen ventaja, el poder de cada uno deriva de su posición en uno o más grupos sociales horizontalmente estructurados (p. 14).

Por supuesto, como el mismo Ferguson reconoce de inmediato, «esta dicotomía entre jerarquía y red es una mera simplificación» (p. 14). Ambos «mundos [...] se encuentran e interactúan» y en «cualquier gran empresa existen redes completamente distintas del "organigrama" oficial» (p. 18). Incluso, en un momento determinado, llega a preguntarse si las redes en el fondo «no son más que empresas muy vagamente estructuradas» (p. 49). Como podía también haberse preguntado si no caben organizaciones que 
combinen, de forma no espontánea sino deliberada, lo jerárquico-formal con lo reticular asimismo formalizado. Es decir, con la existencia, reconocida en el organigrama de una determinada organización jerárquica, de nodos aislados, independientes entre sí, pero conectados por separado con el núcleo o centro de la red, con el fin de que lo que suceda en ellos no afecte al resto de la organización. Pero la dicotomía queda ahí, permanece. Y en ella, las jerarquías -«organizaciones verticalmente estructuradas caracterizadas por un mando, control, y comunicación centralizados y dependientes» (p. 46)- son identificadas con la rigidez, el conservadurismo, la centralización, la pertenencia forzosa y la autocracia, mientras que las redes lo son con la flexibilidad, la innovación o creatividad, la descentralización, la pertenencia voluntaria y el libre espíritu emprendedor.

Este rasgo último, el de poseer un «espíritu emprendedor siempre se ha avenido bien», nos dice Ferguson de sí mismo, «con mi amor por la libertad». Un «amor», recalca, que le ha hecho rehuir la riqueza, el poder político y la carrera académica: «formar parte de la jerarquía», nos dice, «implica rebajarse uno mismo, al menos al principio»; implica períodos «de obligada servidumbre», sufrir «indignidades» $\mathrm{y}$ «humillaciones». "¿No es mejor hoy», concluye, «estar en una red que nos da influencia, que en una jerarquía, que nos da poder?» (pp. 16-17). Y no solo porque vivamos en la era de «la Red» y del «entramado», sino porque «nuestra especie debería conocerse en realidad como Homo dictyous ("hombre en red") puesto que "nuestros cerebros parecen haberse construido para las redes sociales” ( pp. 36 y 40). ${ }^{8}$ El ser humano, «con su incomparable red neural, nació para interrelacionarse» y es ahora, tras «la invención del lenguaje escrito», cuando «las nuevas tecnologías han facilitado nuestra antigua necesidad innata de interrelación» (p. 42). Esta es «la segunda época en la historia» -la primera sería la de la invención y difusión de la imprenta- «en que una serie de instituciones jerárquicas obsoletas se han visto cuestionadas por redes novedosas, cuyo impacto a su vez ha sido amplificado por la nueva tecnología» (p. 77). Somos animales sociales, y «el enigma» en todo caso radica en "por qué y cómo nosotros, maestros de la interrelación por naturaleza, hemos

\footnotetext{
8 Cita tomada de Nicholas A. Christakis y James A. Fowler, Connected: The Surprising Power of Our Social Networks and How They Shape Our Lives (New York: Little Down, 2009), 239. Traducción al castellano: Conectados. El sorprendente poder de las redes sociales y cómo nos afectan (Barcelona: Taurus, 2009).
} 
sido tanto tiempo esclavos de jerarquías verticalmente estructuradas y rígidamente institucionalizadas» (p. 44).

\section{EL ANÁLISIS DE LA REDES SOCIALES: CUESTIONES METODOLÓGICAS}

En las páginas siguientes, y antes de pasar a analizar las redes seleccionadas, Ferguson dedica cinco capítulos a las cuestiones metodológicas que plantea el estudio de las redes sociales: sus orígenes -el sociograma, estudios de psicología social, los índices de citas o impactos-, fundamentos -la «homofilia» o "asortividad»: «tendencia a sentirnos atraídos por personas similares a nosotros» por cualquier razón o aspecto (p. 53)-, variedades -aleatorias, jerárquicas- y representación gráfica de las mismas, su evolución, funcionamiento -vínculos débiles, ideas virales- e interacciones entre redes y estructura -centralidad de grado, de intermediación y de proximidad, coeficientes de agrupamiento, núcleos o centros, nodos, aristas, clústeres o racimos, densidad de la red-.

Tras esta parte teórico-metodológica destinada a dar un aire más científico, técnico-objetivo, a las tesis y afirmaciones del libro -en especial, gracias al acompañamiento gráfico y a la fundamentación en apariencia matemática de este tipo de análisis-, lo que se espera encontrar es una aplicación comparada de dicha metodología a algunos tipos históricos o actuales de redes que muestre su virtualidad, sus posibilidades y, como toda metodología, también sus límites. Sin embargo, lo que el lector se encuentra -tal y como se desprende de la relación anteriormente expuesta- son análisis más o menos breves y detenidos o superficiales de un amplio y diverso número de redes seleccionadas para llevar a cabo una apretadísima síntesis histórica desde el siglo XIV al actual que apoye la tesis central del libro: la importancia -hasta ahora subestimada por los historiadores-, de las redes sociales -cuyo concepto y amplitud no se definen- como espacios de innovación, cambio y emprendimiento frente a las jerarquías, y el relevante papel desempeñado por dichas redes en los procesos y acontecimientos históricos. ${ }^{9}$ ¿No hubiera sido preferible

\footnotetext{
9 En igual sentido se expresó Moises Naim, desde las páginas de The Washington Post, al comentar el libro: «In fact, it is surprising how little Ferguson relies in the initial chapters on network theory to make his case. In the remaining eight parts of the book, this network theory mostly disappears and the story is told in standard historical narrative». En: https://www.washingtonpost.com/outlook/
} 
reducir el número de redes a analizar, llevar a cabo un estudio menos superficial de ellas y comparaciones que permitan establecer algún tipo de relación entre sus rasgos -estructura, densidad, objetivos, componentes, etc.-, su evolución y su funcionamiento? ¿Cómo es posible llegar a conclusión alguna tras analizar de forma rápida casi una treintena de redes de muy diferente tipo? Claro que entonces estaríamos ante un libro quizás académica y científicamente más serio o, si se prefiere, no redactado para llegar a un público amplio y que fuera readable; o sea, al alcance del lector medio: el acostumbrado a pasar de aquí a allá, de un asunto a otro, a lo largo de un elevado número de capítulos (hasta sesenta, en este caso) caracterizados por su brevedad, la aparente diversidad temática y la introducción de vez en cuando de referencias, anécdotas, cometarios o temas llamativos. Es decir, un lector apresurado cuya mente ha sido conformada por un discurso, el televisivo y/o el de las nuevas y tecnológicas redes sociales, dirigido más a entretener, distraer y captar la atención que a pensar con un cierto rigor. "The historical panoramas» que Ferguson ofrece en sus libros, nos dice Moises Naim, «often come mixed with telling anecdotes, illuminating minutiae, fun facts and even some facile one-liners that, while entertaining, don't add much to the argument».10

\section{REDES SELECCIONADAS: FILIAS Y FOBIAS}

La selección de redes efectuada muestra, como es lógico, algunos de los temas que han sido objeto de estudio por Ferguson con anterioridad -el Imperio británico, los Médici, la banca Rothschild, Kissinger...-, así como, al mismo tiempo, sus filias y sus fobias. Uno no puede menos que mostrar su acuerdo cuando señala la presencia y relevancia de las redes sociales en la vida e historia del ser humano. Cualquier estudiante universitario de sociología o psicología social lo sabe, o debe saberlo. Lo extraño es que diga que los historiadores han desdeñado o subestimado dichas presencia y relevancia. Es posible que sus referencias a determinadas redes no hayan ido acompañadas

\footnotetext{
are-scholars-looking-for-history-in-all-the-wrong-places/2018/03/09/2a65208a-1738-11e8-8b08027a6ccb38eb_story.html (consulta efectuada el 20 de septiembre de 2020).

10 https://www.washingtonpost.com/outlook/are-scholars-looking-for-history-in-all-the-wrong-places/2018/03/09/2a65208a-1738-11e8-8b08-027a6ccb38eb_story.html (consulta efectuada el 20 de septiembre de 2020).
} 
de representaciones gráficas o de análisis comparativos, pero cualquier historiador medianamente versado sabe que las redes familiares, clientelares, de sociabilidad popular, comerciales, culturales, científicas, religiosas, heterodoxas, contrahegemónicas, clandestinas o formadas en torno a estructuras no jerárquicas basadas en la amistad, el vecinazgo, los gustos y aficiones, la ayuda mutua, la colaboración, la gestión de bienes o intereses comunes, el trabajo o gremio, etc., vienen siendo objeto de atención preferente por la historiografía desde al menos los años sesenta y setenta del siglo pasado desde la historia social, la cultural, la económica y la política.

Quizás todo se explica a partir de una frase que Ferguson sitúa en las primeras páginas del libro al referirse al origen de su interés por las redes sociales: "Yo había descubierto», dice, "que las élites de Vilfredo Pareto -desde los "notables" de la Francia revolucionaria hasta los Honorationen de la Alemania guillermina- solían ser más importantes que las clases de Karl Marx en el proceso histórico, pero no había aprendido a analizar las estructuras elitistas» (p. 20). Acabáramos. A Ferguson lo que le atrajo en principio, en consonancia con su modo o estilo de vida, fueron las redes elitistas de índole económico-financiera, política o cultural. Y de ahí proceden buena parte de sus filias.

Vayamos con las fobias. Tras atribuir per se a las redes, frente a las jerarquías, la serie de bondades antes mencionada -flexibilidad, innovación o creatividad, descentralización, pertenencia voluntaria y libre espíritu emprendedor- Ferguson se cura en salud y advierte que las redes sociales pueden también tener objetivos malsanos. De algún modo, podría decirse que las hay buenas, malas y, por ahora, ni buenas ni malas. El problema reside en quien o quienes califican tanto a las redes como a sus objetivos y con arreglo a qué criterios. Y aquí es donde aparecen también las fobias. Entre otras razones porque los criterios son geopolíticos y parten del supuesto de que el modelo o democracia -un determinado modelo o democracia- estadounidense es, con los errores de sus gobernantes y sus imperfecciones, el que hubo que salvaguardar en la primera Guerra Fría frente a la Unión Soviética, y el que hay que salvaguardar en la segunda Guerra Fría frente, en este caso, a China y, en la actual sociedad en red, a los cuasimonopolios de las grandes empresas de las redes tecnológicas. No se dice así, de modo tan explícito, pero es lo que se desprende de la lectura del libro. 
El problema no reside tanto en los análisis -que también- cuanto en los adjetivos, las calificaciones, descalificaciones y etiquetados a los que se recurre. Así, al referirse al «alarmante» avance en los años finales del siglo XIX de la izquierda política -marxistas, anarquistas- y del nacionalismo, se califica a estos movimientos sociales y políticos de «sectas utópicas extremistas» (p. 423). Tras referirse a la «pandemia global» de la llamada gripe española de 1918-1920, Ferguson aclara que «no fue esta la única plaga del período comprendido entre 1917 y $1923 »$ cuando «una cepa mutante del marxismo desarrollada por los bolcheviques rusos arrasó asimismo la masa continental euroasiática, al tiempo que nuevas formas extremas de nacionalismo generaban violentos movimientos fascistas en casi todos los países europeos» (p. 248). Y en las páginas dedicadas a la revolución rusa -un capítulo titulado «La peste»no duda en calificar la rápida difusión del «virus bolchevique» en Rusia de «epidemia» o «pandemia proletaria» (pp. 262-263) -el término epidemia se utiliza también en el libro para referirse al «terror islamista» (p. 438) y a la tendencia reguladora del gobierno de Obama (p. 408)-, además de atribuir en parte su triunfo a la carencia de «instinto asesino» en Kerenski.

La equiparación anterior como «sectas utópicas extremistas» del marxismo, el anarquismo y los nacionalismos extremos no debe llamar a engaño. El capítulo dedicado al nazismo lleva, a diferencia del anterior sobre la "peste» bolchevique, un título neutro: «El principio del líder». Y en cuanto a su contenido, caracteriza en parte dicha ideología como un movimiento o "despertar religioso», una «nueva religión política» con su liturgia y su catecismo, y al régimen político nazi como un «caos policrático» en el que diferentes «individuos y organismos rivales competían por cumplir lo que ellos interpretaban como los deseos del Führer» (pp. 271-273). Nada de epidemias, virus y plagas.

\section{REDES SOCIALES Y ANTISOCIALES}

No todas las redes sociales merecen el mismo calificativo o juicio moral. Las hay, dice Ferguson, antisociales. La «banda islamista» que perpetró los atentados del 11 de septiembre de 2001, además de ser una red «terrorista» y de haber sido urdida por una «mente diabólica», era «en verdad una red antisocial, casi invisible, como deben serlo las redes 
secretas para evitar que las detecten»(pp. 391-393). Por el contrario, aunque Ferguson reconozca, cómo no, que «las pruebas de una relación causal entre Irak y los atentados del 11-S rayaban en lo inexistente», no va más allá de considerar un «error» estratégico la intervención militar de Estados Unidos en Irak para derrocar a Sadam Husein ya que solo sirvió para fortalecer y extender la red de $\mathrm{Al}$ Qaeda. ${ }^{11} \mathrm{Al}$ igual que serían errores los «bombardeos estratégicos» ${ }^{12}$ en cuanto acciones dirigidas a terminar con dicha red en oposición al principio de que contra una red ágil solo se puede luchar mediante otras redes (pp. 394-396).

En igual sentido, aunque Ferguson atribuya «la influencia y reputación» de Henry Kissinger sobre todo al establecimiento de redes personales que le proporcionaban una «interconectividad fuera de lo normal», no duda en destacar que tanto una como otra «eran» también "producto [...] de su intelecto y laboriosidad» (p. 349) cualidades que, como es evidente, en ningún momento considera que puedan también poseer los líderes o componentes de las redes que califica de antisociales o de las «sectas utópicas extremistas». En cuanto a su "reputación», baste decir que entre los «acontecimientos geopolíticos» cuya «gestión» se vio facilitada por las redes que tejió en torno a su persona, se hallan no solo las mencionadas por Ferguson -guerra árabe-israelí de 1973, guerra del Vietnam, ...- (p. 344), sino también otras que no considera necesario

11 Las estimaciones sobre las muertes producidas por la Guerra de Irak oscilan entre las $150.000 \mathrm{y}$ el millón de víctimas. En: https://es.wikipedia.org/wiki/Guerra_de_Irak\#P\%C3\%A9rdidas_humanas (consulta efectuada el 10 de septiembre de 2020). Con independencia de ello, la guerra y ocupación de Irak fueron iniciadas a partir, como el mismo Ferguson reconoce, de pruebas inexistentes y, añadimos, sin mediar agresión alguna por parte del país invadido y sin autorización de las Naciones Unidas.

12 La expresión «bombardeos estratégicos» y la referencia a su inutilidad «en una guerra en red» está tomada de John Arquilla, «It takes a Network», Los Angeles Time, 25 de agosto de 2002. El «bombardeo estratégico» es «una estrategia militar utilizada durante una guerra total, que intenta destruir la capacidad económica de una nación para librar la guerra. Es un ataque aéreo sistemático y organizado. [...]. Las misiones de bombardeo estratégico por lo general atacan blancos tales como fábricas, redes ferroviarias, refinerías de petróleo y ciudades completas, mientras que las misiones de bombardeo táctico se dirigen contra blancos tales como concentraciones de tropas, puestos de mando y control, aeropuertos militares y depósitos de munición, que son blancos específicos». En: https://es.wikipedia.org/wiki/Bombardeo_estrat\%C3\%A9gico. La página dedicada al tema en Wikipedia es un tanto confusa, está mal redactada y en ningún momento alude a la necesaria existencia de víctimas civiles en este tipo de bombardeos, ni siquiera con la eufemística expresión de «efectos colaterales». Tampoco es recomendable, en este aspecto, la dedicada al «bombardero estratégico», aunque en ella se indiquen algunos ejemplos de este tipo de estrategia desde la I Guerra Mundial hasta fechas recientes (https://es.wikipedia.org/wiki/Bombardero_estrat\%C3\%A9gico). Consultas efectuadas el 9 de septiembre de 2020. 
mencionar como el golpe de Estado contra Allende en Chile en 1973 y el establecimiento de la dictadura de Pinochet, el llamado Proceso de Reorganización Nacional en Argentina y la dictadura de Videla (19761981), la dictadura cívico-militar en Uruguay (1973-1985), y la Operación Cóndor establecida en 1975 de la que Kissinger es considerado promotor e ideólogo. Nada extraño si se tiene en cuenta que Kissinger fue uno de los fundadores, junto con Rockefeller y la banca Rothschild, del antes mencionado grupo Bilderberg al que Ferguson pertenece. Lo que sucede es que un historiador medianamente serio si alude a la reputación de un personaje como Kissinger no debe pasar por alto -aunque sea en una breve nota a pie página y sin necesidad de pronunciarse en favor de una u otra faceta- que, para unos, se trata de alguien que en 1973 obtuvo el Premio Nobel de la Paz y, para otros, de alguien responsable de violaciones sistemáticas de los derechos humanos e incluso de ser un criminal de guerra. Así, con esta doble cara, se le caracteriza hasta en Wikipedia. ${ }^{13}$

\section{AMENAZAS PARA LA DEMOCRACIA ESTADOUNIDENSE: LAS NUEVAS REDES TECNOLÓGICAS Y LA CIBERGUERRA}

A lo largo del libro se alude o dejan entrever los peligros que han acechado o acechan el modo de vida o democracia estadounidense. Por lo general, se trata de ideologías de amplia difusión mundial originadas en el exterior -comunismo, islamismo- o de países con asimismo pretensiones imperialistas -la URSS durante los años de la Guerra Fría, China en la actualidad-. En todo caso, se trata de amenazas exteriores, no generadas en y por el mismo sistema o modelo. Solo hay una excepción: las nuevas redes sociales tecnológico-electrónicas. Volveré después sobre el tema. Ahora solo aludiré al tratamiento que Ferguson da al triunfo de Donald Trump en las elecciones presidenciales de 2016 y la no consideración como amenaza para la democracia estadounidense de dos aspectos del mismo.

El escenario electoral supuso, a su juicio, «un enfrentamiento catártico entre Clinton -la personificación de la jerarquía establecida- y

\footnotetext{
13 https://es.wikipedia.org/wiki/Henry_Kissinger (consulta efectuada el 9 de septiembre de 2020).
} 
Trump, al que el establishment se tomó literalmente, pero no en serio».14 Por supuesto, ambos candidatos recurrieron a las «redes sociales por medio de plataformas online», pero «en la fase final de las elecciones [...]. Trump contaba con un 32 por ciento más de seguidores en Twiter que Clinton y un 87 por ciento más en Facebook», así como cuatro veces más de likes en Facebook, y sus tuits se retuitearon una media cuatro veces superior a los de Clinton. La conclusión es evidente: el resultado se debió, en buena parte, al uso que Trump y sus partidarios hicieron de dichas redes. Hasta ahí nada hubo en la campaña y en el triunfo de Trump que pudiera significar una amenaza para la democracia, si dejamos a un lado tres aspectos que Ferguson no menciona: la baja calidad y simplificación del lenguaje escrito o visual utilizado dichas redes; el anuncio del director del FBI, efectuado justo antes de la votación -sin tiempo para elaborar y difundir una respuesta desde las redes favorables a Clinton-, de que se estaban investigando sus correos electrónicos; y la existencia de un sistema electoral, establecido en el siglo XVIII, que hace que un voto en determinados Estados valga lo mismo que los de trescientos y pico votantes en otros, dato que explica que Trump ganara las elecciones aun obteniendo 2.800 .000 votos menos que Clinton. Ciñámonos solo a dos de aquellos aspectos que el mismo Ferguson reconoce que ayudaron al triunfo del candidato republicano -además de la injerencia «de la red de inteligencia rusa» (p. 473)-, sin que en ningún momento los enjuicie o tome como indicadores de la calidad de la democracia estadounidense. Uno es el abundante número de bulos-mentiras -fake news-: «De las noticias falsas conocidas que aparecieron en los tres meses previos a las elecciones, las anti-Trump se compartieron en Facebook ocho millones de veces; las anti-Clinton, treinta» (pp. 447-451). El otro se refiere a la «coordinación muy estrecha» que hubo «entre la campaña de Trump y la red alt-right» («derecha alternativa»). No ya porque destacados miembros de la misma se jactaran de haber encumbrado a Trump al actuar como troles desde sus redes (p. 450), ${ }^{15}$ sino por la

14 La referencia a Trump está inspirada en el artículo de Salena Zito, «Taking Trump seriously, not literally», The Atlantic (23 de septiembre de 2016).

15 Trol: «En la jerga de Internet, un trol, plural troles (del noruego troll), describe a una persona con identidad desconocida que publica mensajes provocadores, irrelevantes o fuera de tema en una comunidad en línea, como pueden ser un foro de discusión, sala de chat, comentarios de blog, o similar, con la principal intención de molestar o provocar una respuesta emocional negativa en los usuarios y lectores, con fines diversos (incluso por diversión) o, de otra manera, alterar la conversación normal en un tema de discusión, logrando que los mismos usuarios se enfaden y se enfrenten entre 
misma naturaleza de dicho movimiento o red integrada por grupos de extrema derecha que defienden el supremacismo blanco. ${ }^{16}$

Aunque ambos aspectos sean descritos como algo normal que no afecta, como amenaza o peligro, a la democracia estadounidense, Ferguson sí aprecia dicha posibilidad -incluso para la democracia en generalen el análisis que efectúa de las redes sociales surgidas gracias a internet, en especial de las FANG (Facebook, Amazon, Netflix, Google), Microsoft y Apple, así como de la ciberguerra y de un «mundo», el de hoy, que a «a menudo [... ] recuerda a una red gigantesca al borde al apagón cataclísmico»(p. 463).

Por supuesto, Ferguson no aborda esta cuestión a partir de la relación que pueda existir entre los soportes de la memoria o los datos-información y los modos y maneras de pensar y ver la realidad, aunque se refiera a ella sin profundizar cuando alude al «apetito insaciable de noticias», a "ese hombre y esas mujer repantigados en el sofá cuya atención vaga errática de la televisión de pantalla plana al portátil, al smartphone, a la tablet y de vuelta a la televisión», o a la «mucha gente [que] permanece conectada todas las horas de vigilia de sus vidas» (p. 443).17 También se acerca al tema de modo superficial cuando, en el capítulo

sí [...]. El trol puede crear mensajes con diferente tipo de contenido como groserías, ofensas, mentiras difíciles de detectar, con la intención de confundir y ocasionar sentimientos encontrados en los demás». En: https://es.wikipedia.org/wiki/Trol_(Internet). Consulta efectuada el 9 de septiembre de 2020.

16 «La derecha alternativa (en inglés, alt-right) es un grupo heterogéneo de ideologías de derecha y extrema derecha de origen estadounidense que rechazan a aquellos conservadores que, según su visión, han asumido ideales considerados progresistas, y cuyas políticas irían en detrimento del futuro de la población blanca en Estados Unidos. Igualmente suelen oponerse al neoconservadurismo y en algunos casos al liberalismo, si bien algunos críticos consideran que grupos como los paleolibertarios son parte de la derecha alternativa. Tienen gran actividad en internet; de hecho se acusa a sus miembros de actuar como trolls en la red. La mayoría de miembros de esta ideología son jóvenes, con gran capacidad de activismo en internet, sin jerarquía ni líderes. Es llamado por algunos medios de comunicación como nacionalpopulismo». En: https://es.wikipedia.org/wiki/Derecha_alternativa (consulta efectuada el 9 de septiembre de 2020).

17 Me refiero a los trabajos, entre otros, de Nicholas Carr, Superficiales ¿Qué está haciendo Internet con nuestras mentes? (Madrid: Taurus, 2011), Neil Postman, Divertirse hasta morir. El discurso públi-

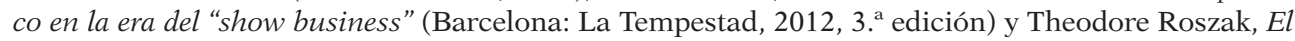
culto a la información. El folclore de los ordenadores y el verdadero arte de pensar (Barcelona: Crítica, 1988). En este último libro puede encontrarse un más detallado y penetrante análisis de la génesis de internet, así como de la mutación de una idea en principio cuasilibertaria de algunos miembros de la generación estadounidense del 68 en la progresiva antropoformización de los ordenadores en detrimento de un pensar libre. 
sobre «La Web 2.0», señala «la discrepancia» existente «entre el ideal y la realidad». Entre el paradigma de Linux expuesto por un programador libertario, Eric S. Raymond, para elaborar un sistema operativo mundial de código o software perpetuamente abierto «a base del hackeo a tiempo parcial de varios miles de desarrolladores»-es decir, de una «comuna virtual» de hackers voluntarios-, ${ }^{18}$ y la extinción «del sueño del código abierto» con «el auge», en este campo, "de los monopolios y duopolios». Una transformación que significó, en palabras de Ferguson, el paso desde «la innovación y la anarquía creativa» a «la comercialización» y a los intentos infructuosos, hasta el momento, de «regulación» (pp. 411-412).

Nadie ni nada parece estar seguro, libre de ataques, en el mundo digital y en la ciberguerra que tiene lugar en lo que Ferguson llama «Ciberia». Ya no es, nos dice, que «los hackers y trolls rusos» sean "una amenaza para la democracia estadounidense similar a la que representaban los sacerdotes jesuitas para la Reforma inglesa: una amenaza interior con apoyo exterior» (p. 473), sino que «al principio eran hackers adolescentes los que causaban estragos» y hoy "gran parte de los ciberataques siguen siendo obra de actores no estatales: vándalos, adolescentes, delincuentes, "hacktivistas" u organizaciones terroristas» (pp. 473-474). "¿Pueden, se pregunta Ferguson, estos "buenos actores” [el Pacto Europeo de los Alcaldes para el Clima y la Energía o la Alianza para el Gobierno Abierto lanzada por Obama] unirse en una nueva clase de red geopolítica y aplicar su "redería" contra los malos actores?». La respuesta de Joshua Cooper Ramo, que Ferguson ofrece a los lectores, es más que dudosa. Para este autor, «la amenaza fundamental para los intereses americanos no son ni China, ni Al Qaeda ni Irán. Es la evolución de la propia red». Por ello, Cooper Ramo defiende, aclara Ferguson, «el levantamiento de "barreras" reales y virtuales para impedir la entrada de los rusos, los delincuentes online, la red de vándalos adolescentes y demás

18 Paradigma expuesto en su «manifiesto del código abierto» The Catedral and the Bazaar: Musings on Linux and Open Source by an Accidental Revolutionary (Pekin y Cambridge: O'Reilly Media, 1999). Los traductores aclaran, en nota a pie de página, que «hacker se usa en este contexto, no en relación con actividades de piratería informática, sino para referirse a todos aquellos que con sus hacks, "mejoras", contribuyen -"con entusiasmo (casi obsesivamente)", como recoge su propia definiciónal desarrollo colaborativo de un software de código abierto» (p. 411). La propia transformación del significado de dicho término, desde la mejora colaborativa a la piratería es ya un claro síntoma de la degradación democrática del sistema. 
malhechores» ${ }^{19}$ No parece ser esta la opción de Ferguson, quien se inclina más por una solución algo confusa, por no decir ingenua e irreal, frente a los «ataques constantes» de «cretinos y granujas» a que se «hallan sometidas» nuestras redes financieras, sociales, comerciales e infraestructurales: crear redes más sencillas en las que la destrucción de un número determinado de nodos no suponga la de la red en su conjunto (pp. 476-477). Esta es al menos la conclusión que este comentarista obtuvo tras la relectura de los párrafos dedicados al tema sin saber que, como se verá después, en un capítulo posterior propone la regulación y el control de las nuevas redes tecnológicas por una pentarquía de grandes potencias.

No es la ciberguerra, para Ferguson, la única amenaza para la democracia e intereses estadounidenses cuyo origen se halle en internet. Por un lado, como ya se indicó, constata la discrepancia entre el ideal -o, al menos, los objetivos originalmente expresos de las FANG- y la realidad. El ideal publicitado va desde el «organizar la información y asegurar que sea útil y accesible a todos» de Google a «Facebook no se creó para ser una empresa. Se construyó para desempeñar una labor social: hacer del mundo un lugar más abierto y conectado», tal y como se dice en $E l$ pequeño libro rojo redactado con el fin explicar a los «nuevos empleados» de Facebook «la misión, historia y cultura» de la nueva compañía (p. 414). ${ }^{20}$ La realidad es harto diferente: las grandes redes digitales son, de hecho, empresas jerárquicas y publicitarias en las que «el usuario es el producto» (p. 417), y el código abierto ha pasado a ser un mercado duopolístico (Microsoft y Apple) en el que predominan los cuasimonopolios (Facebook -objeto de las mayores críticas por parte de Ferguson-, Amazon, Google). Una situación, y no otra, que es la que ha hecho posible no solo que sus propietarios figuren entre los hombres más ricos del mundo- (p. 418), sino también que conviertan la información personal que almacenan en un objeto de compra y venta, y la publicidad en noticia dirigiendo en un sentido u otro las preferencias, aficiones y gustos de quienes utilizan dichas redes (pp. 412-420).

\footnotetext{
19 Joshua Cooper Ramo, The Seventh Sense. Power, Fortune and Survival in the Age of Netwoks (New York: Little Brown, 2016), p. 182. Donde dice americanos, léase, por favor, estadounidenses. Sobre la inclusión de «los rusos» entre los «demás malhechores», sobra todo comentario.

20 En: https://v1.benbarry.com/project/facebooks-little-red-book (consulta efectuada el 12 de septiembre de 2020).
} 
Por otro lado, la sociedad estadounidense, nos dice Ferguson, ha devenido, en las últimas dos o tres décadas, una sociedad «desmembrada» (pp. 421-426). En buena medida, por el crecimiento de la desigualdad, un rasgo, aclara, apreciable tanto a nivel mundial como en Estados Unidos. La representación gráfica de «la jerarquía de la riqueza y los ingresos", en un caso y en el otro, "posee la forma de un edificio con una base muy ancha y una aguja sumamente alta y afilada» (p. 422). Constatado el hecho, por lo demás innegable, Ferguson no parece extraer de él sus consecuencias obvias e incurre, a juicio de este comentarista, en incoherencias. La globalización económica y financiera y de los flujos de información ha hecho posible, a su juicio y en clara contradicción con lo anterior, «una redistribución global más eficiente del capital y de la mano de obra», así como «una mejora significativa» de las «condiciones de vida» de la «mayor parte de la gente del planeta» durante "los últimos treinta o cuarenta años» (p. 423). Sin embargo, eso no ha sido así en el interior de algunos países, entre ellos Estados Unidos donde «es evidente que ocurre algo» entre "los estadounidenses blancos (no hispanos)», en especial «los de mediana edad que solo llegaron a cursar secundaria» cuyos índices de mortalidad se han visto reducidos (p. 424). De un modo u otro, «el aumento de la polarización política y social» ha sido «una característica de las dos o tres últimas décadas» en Estados Unidos. Un proceso evidente que hubiera merecido un análisis más profundo -en relación, por ejemplo, con el crecimiento de la desigualdad-sobre el que Ferguson se limita a considerar que sus «rasgos más destacados son una marcada contracción de las redes centrales de debate de los estadounidenses, que contienen menos miembros ajenos a la familia que en el pasado, y un debilitamiento de las instituciones tradicionales de red, como las centradas en la iglesias y las asociaciones locales de voluntarios» (p. 426). Una relación en la que Ferguson no considera que deban incluirse otras redes tradicionales de la sociedad estadounidense como, por ejemplo, las sindicales especialmente debilitadas, entre otras razones, por el macartismo en los años de la Guerra Fría y las políticas estatales y federal del Partido Republicano.

\section{CONTRADICCIONES E INCOHERENCIAS}

No parece que Ferguson, como la casi totalidad de los mortales, posea el «privilegio» que Werner Jaeger atribuía a Platón al referirse a su 
capacidad para recrear y transmitirnos la figura y el pensamiento de Sócrates: el de «de ver en enfoque histórico la propia época e incluso la propia vida». ${ }^{21}$ En efecto, una cosa es analizar las redes de los Médici o de los Rothschild, incluso de las redes culturales que hicieron posible la Revolución francesa, y otra cosa es intentar escrutar y entender el mundo en el que uno vive, tanto si lo disfrutas como si lo padeces. Si, además, el propósito del libro es ofrecer una visión más o menos rápida y superficial de la influencia de las redes en diversos acontecimientos o procesos con el fin de llamar la atención sobre este fenómeno hasta ahora, al parecer, subestimado por los historiadores, no es extraño que, al exponer y analizar los cambios tecnológicos, políticos, económicos y culturales más recientes, se aprecien algunas contradicciones e incoherencias.

Por un lado, Ferguson reconoce, cómo no, que la sociedad estadounidense es hoy más desigual y se halla más polarizada política y socialmente que hace dos décadas. Por otro, se muestra crítico y receloso tanto ante el creciente poder y riqueza de los grandes gigantes tecnológicos como ante su regulación y control por las jerarquías estatales. Además, en la más pura línea de la derecha conservadora estadounidense -en uno de cuyos think tank ha elaborado el libro- repudia lo que llama el «Estado administrativo» de Obama hasta llegar a preguntarse por qué Washington, bajo su mandato, «ha degenerado [...] en una versión de aquel Estado burocrático hipertrófico que imaginó en su día Franz Kafka» (p. 408).

Asimismo, Ferguson reconoce, como vimos, el crecimiento de la desigualdad y de la polarización social y política en Estados Unidos, incluso de la mortalidad entre la población blanca -en todo caso, una tasa inferior a la de la población afroamericana o hispana, aunque no lo mencione-. Sin embargo, se pronuncia en contra de la «epidemia reguladora» de la administración Obama -en la que incluye el programa Medicare destinado a implantar una tímida atención sanitaria universal-, así como de su imposición al sector privado de unas «cargas que acaban por reducir la tasa de crecimiento y la creación de empleo» (p. 410), y sostiene, desde una perspectiva global, que «proporcionar telefonía móvil a los pobres del mundo está resultando más fácil que proporcionarles

21 Werner Jaeger, Paideia. Los ideales de la cultura griega (México: Fondo de Cultura Económica, 1962, 2. ${ }^{a}$ edición), 455. 
agua potable; quizá sea un argumento a favor de dejar la provisión de agua potable en manos del sector privado en lugar de a gobiernos débiles y corruptos» (p. 467). ${ }^{22}$ En síntesis, menos impuestos para las rentas altas, Estado mínimo e iniciativa privada sin regulación. Justo, a juicio de este comentarista, el tipo de sistema económico que produce ese incremento de la desigualdad y de la polarización que Ferguson caracteriza, acertadamente, como rasgos negativos de la sociedad estadounidense de las dos últimas décadas. En este sentido, podríamos decir que su libro sería el anti-Piketty. ${ }^{23}$

Item más, por un lado, valora positivamente los efectos de la globalización mundial financiera y de la mano de obra (p. 423). Por otro, no duda en atribuir en parte la crisis financiera de 2008, provocada por la quiebra de Lehman Brothers y la burbuja inmobiliaria estadounidense, a un claro ejemplo de dicha movilidad: «la llegada al país de flujos de capital de los mercados emergentes» -es decir, de otros países-, «en particular de China» (p. 402). O sea, a la misma globalización financiera.

Por último, y esto afecta de lleno a las tesis centrales del libro y a las preocupaciones de Ferguson en relación con el tiempo presente, el gran valedor de las redes frente a las jerarquías se ve obligado en las páginas finales a responder a dos preguntas que él mismo formula:

¿Nos liberarán las nuevas redes de los grilletes del Estado administrativo como liberaron las redes de los siglos XVI, XVII y XVIII a nuestros ancestros de los grilletes de la jerarquía espiritual y secular? ¿O tal vez las jerarquías establecidas en nuestro tiempo lograrán más rápido que sus predecesoras imperiales asimilar las redes y enrolarlas en su antiguo vicio de entablar guerras? (p. 487).

Su diagnóstico no es optimista. Por un lado, la ilusoria «utopía libertaria» de ciberciudadanos ${ }^{24}$ «libres e iguales [...] interconectados y compartiendo todos los datos disponibles» en un ambiente de «transparencia»y

\footnotetext{
22 Afirmación basada o tomada de World Bank Group, Digital Dividends (Washington D.C: International Bank for Reconstruction and Development, 2006), 95.

23 Me refiero a Capital e ideología (Barcelona: Planeta, 2019), cuya edición original francesa aparecería dos años después de la obra de Ferguson.

24 En el original netizens.
} 
«seguridad», ha sido sustituida por la fantasía romántica de la posibilidad -bajo el nombre de inteligencia artificial y el impulso de la robótica- de un "cerebro global» o "superorganismo planetario" capaz de autoorganizarse» (p. 487) que, a juicio de Ferguson, nos llevaría al «desempleo a gran escala» y a la implantación consiguiente de una "renta básica modesta pero suficiente». Es decir, a un «pacto social» solo «viable» mediante un «totalitarismo que recurriese a los sedantes, como el que imaginó Aldous Huxley» (p. 489). Por otro, han surgido «redes nuevas y gigantescas» de «estructura jerárquica» que pueden ser instrumentalizadas por «oligarcas corruptos o fanáticos religiosos para lanzar una guerra nueva e impredecible en el ciberespacio. Esa contienda ha comenzado. Los índices de riesgo geopolítico señalan que quizás no estemos tan lejos de una guerra convencional e incluso nuclear» (p. 489). Y en este tema, «la historia», afirma el mismo Ferguson que al comienzo de la obra atribuía toda suerte de virtudes y bienes a las redes frente a las jerarquías, «nos ha enseñado que confiar en las redes para dirigir el mundo es una forma segura de acabar en la anarquía». Quienes «vivieron las guerras de las décadas de 1790 y 1800 », tras la revolución francesa, "aprendieron una lección importante [...]: a menos que uno quiera cosechar una tempestad revolucionaria tras otra, es mejor implantar algún tipo de orden jerárquico en el mundo y darle un poco de legitimidad. [...] un mundo dirigido por redes [será] un mundo dividido entre las FANG y las BAT y propenso a todas las patologías [...]; un mundo donde subredes malignas se aprovecharán de las posibilidades de la World Wide WEB para propagar, como si fuesen virus, memes y falsedades» (pp. 489-490).

Tras este giro de $180^{\circ}$ en su valoración de las redes, una vez que los cambios tecnológicos han puesto estas al alcance de cualquiera, su «alternativa» no pasa de ser una más o menos ingenua, bienintencionada -o interesada- propuesta: dado que «ningún Estado puede aspirar a gobernar Ciberia por mucho tiempo», la "alternativa es que una nueva pentarquía de grandes potencias asuma el interés común de resistir la difusión del yihadismo, la delincuencia y el cibervandalismo, por no mencionar el cambio climático» (p. 490). ${ }^{25}$ Una forma como otra de

\footnotetext{
25 Suele ser norma -y ardid-, entre los partidos o grupos de ideología neoconservadora sustituir la expresión «calentamiento global», de índole general y atribuible al ser humano, por la de «cambio climático», de naturaleza ocasional, variable estacionalmente y aparentemente independiente de la acción humana.
} 
reconocer el declive de la supremacía estadounidense y la necesidad de llegar a un pacto de no agresión entre esas cinco grandes potencias, que Ferguson no precisa -Estados Unidos, China, Rusia, Inglaterra, ¿Alemania, Francia, Europa, India...?-. Un pacto similar al de los fracasados acuerdos de la época de la Guerra Fría y años posteriores dirigidos a limitar el número de países poseedores de armas nucleares.

\section{¿HISTORIA O UN ENSAYÍSTICO BESTSELLER HISTÓRICO?}

Nada que objetar, al contrario, al hecho de que los historiadores profesionales escriban ensayos sobre temas históricos dirigidos, como es el caso, a un público culto e interesado por el tema. Es en ese sentido en el que considero que estamos más ante un ensayo histórico que ante un libro de historia, lo que no tenía que significar, por sí mismo, pérdida de rigor. Y aquí es donde el libro de Ferguson deja mucho que desear.

Aunque parezca extraño, nunca se define lo que se entiende o qué es una red social. Esto es así hasta tal punto que en la página 31 los traductores se ven obligados a introducir una nota a pie de página en la que se aclara que el término red social «debe entenderse aquí en un sentido amplio, en referencia a una estructura que opera en el seno de una sociedad, y no en la acepción restringida actualmente predominante para referirse a servicios como Facebook, Twitter, etcétera». Nota, por lo demás, errónea y confusa: no toda «estructura que opera en el seno de una sociedad» puede calificarse de red social; además, es obvio que Ferguson incluye en el concepto red social a Facebook, Twitter, etcétera, y así las considera y analiza en su libro.

Tampoco se indica, en ningún momento, cuáles son los rasgos que caracterizan a una red social ni se establece una tipología mínima de ellas en función de su tamaño, densidad, objetivos, transparencia/opacidad, componentes, grado de formalización, inserción o no en una estructura jerárquica, etcétera, sin que haya nada en la abigarrada y apresurada exposición de las redes sociales referidas en el libro que permita extraer algún tipo de conclusión más o menos general sobre las mismas, mediante un mínimo análisis comparativo que tuviera en cuenta dichas características y el contexto social, político, económico y cultural en el que operan. A lo más que se llega es a distinguir entre redes sociales y antisociales o malignas; entre el reino del bien y el del mal. Una 
distinción basada en criterios subjetivos y, por tanto, susceptible de aplicarse con arreglo a muy distintos criterios y modos.

La razón de esta falta de rigor es obvia. Lo que se ha buscado ha sido producir un bestseller histórico con abundante material gráfico, ágil lectura y capítulos breves -hasta 60 con un epilogo y un apéndice-. Su precio en el mercado (26,50 euros), en relación con sus características como libro -651 páginas, tapas duras, sobrecubiertas en color, buen papel, abundantes grafos e ilustraciones, algunas en color-, nos hace sospechar que la edición en castellano de esta obra ha tenido que tener algún tipo de subvención por parte de instituciones o grupos -redes- afines al neoconservadurismo, cuyas ideas contribuye a difundir subliminal o expresamente.

Una última observación. ¿De dónde procede el título de La plaza y la torre? Todo se aclara en el epílogo bajo el título de «La plaza y la torre originales: redes y jerarquías en la Siena del Trecento». Un toque o brochazo histórico-artístico queda muy bien en una obra de este tipo. Si los grafos aportan objetividad científico-matemática, el arte colorea la obra, aunque la referencia sea algo rebuscada, por no decir forzada.

La plaza y la torre son la Piazza del Campo de Siena y su Torre Mangia. Las redes-plazas y las jerarquías-torres son alegóricamente imaginadas por Ferguson a partir de los tres frescos de Ambrogio Lorenzetti, pintados en 1338-1339 para «servir de inspiración a los nueve cargos electos que dirigían la República de Siena» (p. 495), que se hallan en la Sala dei Nove del Palazzo Pubblico, ubicado asimismo en dicha plaza. Dos de dichos frescos, conocidos con los nombres de «Guerra» $\mathrm{y}$ «Paz», deben ser entendidos, según Ferguson, «como el contraste, más antiguo, entre la armonía cívica y el conflicto que puede desencadenar un gobierno tiránico» (pp. 497-498). En el tercer fresco, el central, veinticuatro miembros de la élite urbana de la que se elegían los nueve que a lo largo de dos meses iban a regir la ciudad desde el Palazzo, separados de sus familias, sostienen una cuerda que une las virtudes de la Justicia y la Concordia con la figura del Bien Común. Para Ferguson, esa cuerda "que enlaza a toda la élite urbana, y que la conecta con los principios de la justicia y el propio bien común» constituye, nada más y nada menos, que «una anticipación de la concepción moderna de la red social y, en efecto, política», y los frescos de Lorenzetti una defensa de la «ciudad-estado 
autogobernada, y hostil tanto a la monarquía como al imperio» dos claros ejemplos de jerarquías tiránicas (p. 498). En plena ceremonia de la confusión final, Ferguson no puede dejar de reconocer que «considerar al artista como un profeta de la Era de la Red que nacería un siglo y medio más tarde sería ir demasiado lejos». Sin embargo, añade, no hay duda de que «se adelantó a su tiempo al vincular de un modo explícito un gobierno basado en el imperio de la ley con la prosperidad económica y la cohesión social» (pp. 498-500).

Si se hubiera prescindido del epílogo, así como de algún capítulo tangencial -por ejemplo, el de las relaciones entre Isaiah Berlin y la poetisa rusa Anna Ajmátova perseguida, por ello, por el régimen soviético-, y de digresiones, anécdotas y referencias personales destinadas en ocasiones al chismorreo -como las «juergas» alcohólico-eróticas de dos espías ingleses al servicio de la URSS (p. 292), o las orientaciones sexuales de Keynes y de los componentes del grupo de Bloomsbury-, quizás Ferguson hubiera dispuesto de tiempo y páginas para explicarnos, sin filias ni fobias ideológicas, qué es una red social, cuáles son sus rasgos, qué variedades existen y que tipo de influencia han tenido en determinados acontecimientos y procesos históricos en función de sus características y del contexto. De modo también entretenido, pero riguroso; una cosa no quita la otra. De ahí que este comentarista suscriba las palabras de Andrew Anthony publicadas en The Guardian tras la aparición del libro. Lo que mejor sabe hacer Ferguson «is to jump around history taking fascinating empirical facts from one place, compelling anecdotes from another, and pulling it all together into a powerful fast-paced narrative». Ese es su estilo, su modo de escribir historia. «The problem», continua Anthony, «is that are simply many strands and too much disparate information for a coherent thesis to emerge». Es cierto que la amplitud de sus referencias «is impressive [...], but his conclusions are underwhelming». ${ }^{26}$

\section{Nota sobre el autor}

Antonio Viñao Frago es Doctor en Derecho y Colaborador Honorario del Departamento de Teoría e Historia de la Educación de la Universidad de

\footnotetext{
26 https://www.theguardian.com/books/2017/sep/24/niall-ferguson-square-and-tower-networks-hierarchies-review (consulta efectuada el 20 de septiembre de 2020).
} 
Murcia. Ha sido miembro del Comité Ejecutivo de la International Standing Conference for the History of Education (1996-2000) y presidente de la Sociedad Española de Historia de la Educación (2001-2005), así como director del Centro de Estudios sobre la Memoria Educativa (2009-2013) y de la revista Historia y Memoria de la Educación (20142019).

Sus campos de investigación son la historia de la alfabetización y de la cultura escrita (la lectura y la escritura como prácticas socioculturales), de la escolarización y de la enseñanza secundaria, la historia del currículum (espacios y tiempos escolares, disciplinas), del profesorado (profesionalización, autobiografías y memorias), y de la memoria escolar y el patrimonio histórico-educativo, así como de la relación entre las culturas escolares y las reformas y políticas educativas.

\section{REFERENCIAS}

Anthony, Andrew. «The Square and the Tower by Niall Ferguson review». The Guardian. https://www.theguardian.com/books/2017/sep/24/niall-ferguson-square-and-tower-networks-hierarchies-review

Arquilla, John. «It takes a Network», Los Angeles Time, 25 de agosto de 2002.

Carr, Nicholas. Superficiales ¿Qué está haciendo Internet con nuestras mentes? Madrid: Taurus, 2011.

Christakis, Nicholas A. y Fowler, James A. Connected: The Surprising Power of Our Social Networks and How They Shape Our Lives. New York: Little Down, 2009.

Ferguson, Niall. La plaza y la torre. El papel oculto de las redes en la historia: de los masones a Facebook. Barcelona: Random House, 2018.

Naim, Moises. «Are scholars looking for history in all the wrong places?». The Washington Post. https://www.washingtonpost.com/outlook/are-scholarslooking-for-history-in-all-the-wrong-places/2018/03/09/2a65208a-173811e8-8b08-027a6ccb38eb_story.html

Postman, Neil. Divertirse hasta morir. El discurso público en la era del «show business». Barcelona: La Tempestad, 2012, 3. a edición.

Ramo, Joshua Cooper. The Seventh Sense. Power, Fortune and Survival in the Age of Netwoks. New York: Little Brzown, 2016.

Raymond, Eric S. The Catedral and the Bazaar: Musings on Linux and Open Source by an Accidental Revolutionary. Pekin y Cambridge: O'Reilly Media, 1999. 
Roszak, Theodore. El culto a la información. El folclore de los ordenadores y el verdadero arte de pensar. Barcelona: Crítica, 1988.

Zito, Salena. "Taking Trump seriously, not literally». The Atlantic, 23 de septiembre de 2016. 